\title{
A Visualized Analysis of the Research Literature on Early Childhood Family Education in China
}

\author{
Cong Liu', Mohd Nazri Bin Abdul Rahman', Xiaopan Yu1, Linlin Yuan² \\ ${ }^{1}$ Faculty of Education, University of Malaya, Kuala Lumpur, Malaysia \\ ${ }^{2}$ Mianyang Teachers Kindergarten, Mianyang, China \\ Email: pva180115@siswa.um.edu.my
}

How to cite this paper: Liu, C., Rahman, M. N. B. A., Yu, X. P., \& Yuan, L. L. (2021). A Visualized Analysis of the Research Literature on Early Childhood Family Education in China. Open Journal of Social Sciences, 9, 347-362.

https://doi.org/10.4236/jss.2021.911025

Received: October 13, 2021

Accepted: November 27, 2021

Published: November 30, 2021

Copyright $\odot 2021$ by author(s) and Scientific Research Publishing Inc. This work is licensed under the Creative Commons Attribution International License (CC BY 4.0).

http://creativecommons.org/licenses/by/4.0/

(c) (i) Open Access

\begin{abstract}
As the most important place for preschool children to grow and learn, family has a great impact on the physical and mental development of preschool children. What is the development process and current status of early childhood family education in China? It is very necessary to visually analyze research status, hotspots and trends of Chinese early childhood family education research field. The quantitative and visual atlas of research literature provide an effective analytical approach for the development of research field. The research data is from CNKI which is the largest and most authoritative literature database in China. The research tool CiteSpace analysis software is used to conduct quantitative analysis on the source data and calculate the core authors, institutions, research hotspots and frontier. Research hotspots and frontiers in the field of early childhood family education in China calculated by CiteSpace software include home-kindergarten cooperation research, rural preschool left-behind children family education research, preschool floating children family education research and preschool children parental education research. Literature content analysis as a qualitative research method makes an in-depth interpretation of research hotspots and frontiers on the basis of quantitative analysis, in order to understand the status quo of Chinese early childhood family education.
\end{abstract}

\section{Keywords}

Chinese Preschool Children, Family Education, Hotspots and Trend, CiteSpace

\section{Introduction}

Family is the main place for learning and growth of children, especially $0-6$ 
years old before official primary school education. Family education has an important impact on academic performance, personality development, mental health, self-esteem, behavioral problems and other developmental outcomes of children (Spera, 2015; Reti et al., 2002). In China, family education is the party's seventeenth session of the sixth plenary session of the special mention of an aspect, how to coordinate school education, family education and social education, is we should and need to take some practical measures of the important subject. In current world, the tide of education reform is overwhelming. Since the 1980s, many countries have been formulating education reform plans and measures according to the world development trend and their specific situations. One of the important characteristics is that in the government's education reform plans. The importance of family education implementation methods and strategies has made specific description or provisions. Therefore, to give full play to the important role of family education in the process of children's young growth, parents should establish correct education concepts, master scientific education methods, respect children's health taste, cultivate children's good habits, strengthen communication and cooperation with the school.

The findings: A good student, a product's noble achievements after they step into the society, and he was mostly affected by good family influence and has a direct relationship. And the problem that the school students, and exposed the problems after they step into the society, can be to find root cause in the family environment and family education (Research Group, 2012). With the development of economic growth, talent competition is increasing, which leads to the emergence of utilitarian education value orientation for parents. The parents of preschool children only focus on the knowledge acquisition of preschool children and neglect the most important personality shaping at this stage ( $\mathrm{Li}, 2010)$. In addition, with the acceleration of urbanization in China, migrant workers have become the norm to work in cities. However, the preschool family education of migrant workers has become a thorny issue that needs to be solved urgently (Du, 2006). In addition, the wrong education methods in family education of preschool children in China mainly include mental violence, over-indulgence, material stimulation and indulgence. These unscientific educational methods are not conducive to the positive development of preschool children (Guo, 2012). What is the current situation of family education for preschool children in China, what problems exist and how to solve them are the key topics of current attention of Chinese education departments. Whether the research field of family education for preschool children in China pays attention to the research issues within the subject, and what are the hotspots and frontiers of the research field? These are the reasons for the quantitative and visual analysis of the literature in this field in this paper. The aim of this paper is to make a quantitative and visual analysis of the literature of early childhood family education in China, which can clarify the development context and process of the research on early childhood family education in China, and analyzes the hot research topics and research frontiers of this field. 


\section{Research Data and Tool}

\subsection{Data Source}

The literature resources were selected from CNKI website which is the largest literature retrieval platform in China. In CNKI platform, the words "early childhood" and "family education" as the main topics, and the period was set from 2000 to 2020. A total of 736 literature were retrieved, and 542 literature were exported after the conference, newspaper, book review and other contents were excluded. Then the retrieval function of literature title, keywords and abstract was used, and the second retrieval was set to include early childhood and family education in the retrieval, and the time period was also set to 2000-2020. A total of 633 literature were retrieved, and 475 literature were retained after filtering one by one. Data cleaning was carried out for the twice retrieved and retained literatures, that is, information incomplete literatures were removed and duplicate literatures were removed. Finally, the research data was determined as 582 literature that could be analyzed.

\subsection{Visual Tool}

The analysis tool used in this study "CiteSpace 5.6.R5" is a literature quantitative and visual analysis software developed by Professor Chen Chaomei of Drexel University in the US. The research tool CiteSpace software is a Java application for analyzing and visualizing co-citation networks (Chen, 2006). This software can perform multi-dimensional, dynamic and time-sharing visual analysis of the structure and development dynamics of the research field. By measuring the literature (collection) of specific fields, CiteSpace explores the critical path of discipline evolution and its knowledge inflection point, and forms the analysis of the potential dynamic mechanism of discipline evolution and the exploration of the frontier of discipline development through the drawing of a series of visual maps (Chen, Chen, Liu, Hu, \& Wang, 2015). The functions of CiteSpace tool mainly include author cooperative network analysis, institutional cooperative network analysis, national cooperative network analysis, subject co-occurrence analysis, keyword co-occurrence analysis, WoS database classification co-occurrence analysis, literature co-citation analysis, author co-citation analysis, journal co-citation analysis, literature coupling analysis. The exported literature data of CNKI database just preserved the literature title, author information, journal information, abstract and keywords, but did not export the reference information, so it could only carry out the first five types of analysis of the above functions.

\subsection{Descriptive Statistical Analysis}

\subsubsection{Annual Publications Trend of Early Childhood Family Education Papers}

Through the metrological analysis of the literature resources, the number of early childhood family education papers between 2000 and 2020 is presented in Figure 1. 
Number of published papers

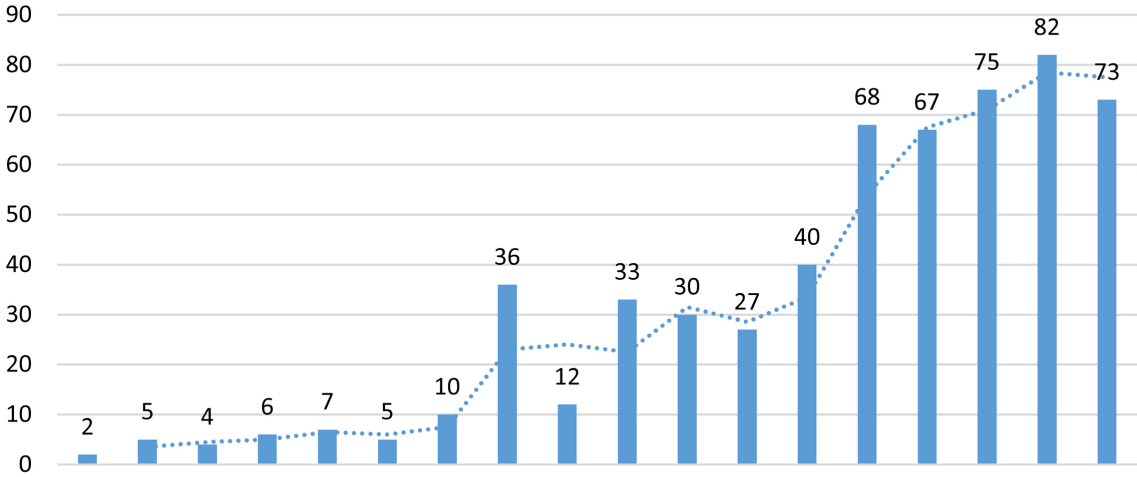

200320042005200620072008200920102011201220132014201520162017201820192020

- Year

Figure 1. The number of published papers of early childhood family education in CNKI.

As shown in the figure, research literature in the field of early childhood family education in China there were first published two papers in 2003, which were master thesis of Southwest Normal University Yin Fang (Yin, 2003) "Study on the Status Quo of parent-child Games among Children in Chongqing Main Urban Area", and Shandong Normal University graduate student Yue Ai Feng's master thesis (Yue, 2003) "Since 1978 kindergarten and the Value of Family Relationship Policy Analysis in China". China began to pay attention to the early childhood family education in the early 21st century, among which the macro-level family education policy and the micro-level parent-child game development status were the first research direction that researchers paid attention to in this field.

The total amount of research literature on early childhood family education presented a stable rising trend. In 2010 and 2016, the total number of publications rose sharply, because the All-China Women's Federation issued the National Guideline for Family Education in 2010 and nine departments including the All-China Women's Federation in 2016 issued Five-year Plan for Guiding and Promoting Family Education (2016-2020).

From that, policy support at the national level will directly lead to an increase in the amount of academic research in that field. Thus, to a great extent, the development of Chinese academic research needs to be promoted by national macro policies.

\subsubsection{Authors and Research Institutions Analysis}

In CiteSpace interface set analysis literature fixed number of year for 2000-2020 time slice unit for one year, the network node set the author co-occurrence network analysis and institutional co-occurrence network analysis respectively. It can get the data of paper 582 most influential authors and institution co-occurrence network graph. Because of early childhood family education research field in China did not form the core authors and institutions cooperation network, research literature just finished by a single author and a single institution. That can 
mean enough across different institutions in the field of cooperative research almost non-existent. The statistical charts of the authors and publishers with the highest influence on the data of 582 literatures can be obtained (Table 1).

In this study, a total of 582 literature data involved 124 institutes, consisting of institutions of higher learning and secondary units, kindergartens, early education institutions, maternal and child health care hospitals and other diversified institutions. The top five institutions are universities in China, which have published the most papers in this field, however the front-line teachers of early childhood education have seldom participated in this research field.

\subsection{Keywords Analysis}

\subsubsection{Keywords Co-Occurrence Analysis}

Research hotspots are the research problems or topics discussed in a relatively large number of papers within a certain period of time (Qiu, Pan, \& Hou, 2014). Keywords are highly generalized by researchers to the core contents of the literature. Therefore, quantitative statistics on the frequency of keyword co-occurrence in a certain period can indicate the research hotspots in this field. Transcoding the data of 582 articles and then combined synonymous keywords, and excluded fuzzy keywords. At the CiteSpace home page, setting time interval of 2000-2020 with time span as one year, choosing node type as keywords co-occurrence analysis. Moreover the threshold was set to the value is 100 which is each time slice unit within the top 100 high-frequency node. To highlight important nodes and simplify the network structure the research chose Pathfinder way of pruning, running software to get the data of paper 582 keywords co-occurrence analysis graph (Figure 2). The larger the circle figure of the node in the graph, the more frequently the corresponding keywords co-occur. The larger the node font is, the stronger the keyword centrality will be, which indicates the probability that the keyword appears with other keywords, in addition the centrality value of a node $>0.1$ is referred to as the critical node.

Keywords with co-occurrence times greater than 10 are sorted by co-occurrence frequency, as shown in Table 2. Combined with the analysis of keywords co-occurrence frequency and centrality in Figure 2 and Table 2, the research hotspots in the field of early childhood family education in China mainly include

Table 1. The co-occurrence of authors and research institutions of early childhood family education in CNKI.

\begin{tabular}{cccccc}
\hline No. & Frequent & Author & NO. & Frequent & Institution \\
\hline 1 & 4 & Miao Chun Feng & 1 & 30 & East China Normal University \\
2 & 4 & Shu Tan & 2 & 25 & Southwest University \\
3 & 3 & Wang Xiao Feng & 3 & 24 & Shaanxi Normal University \\
4 & 3 & Li Meng Ming & 4 & 20 & Northwest Normal University \\
5 & 3 & Cang Cui & 5 & 19 & Central China Normal \\
& & & & & University \\
\hline
\end{tabular}


C. Liu et al.

Table 2. Keywords co-occurrence frequency sort of early childhood family education.

\begin{tabular}{cccc}
\hline No. & Count & Centrality & Keywords \\
\hline 1 & 105 & 0.53 & Early childhood education \\
2 & 104 & 0.33 & Family education \\
3 & 96 & 0.38 & Preschool children \\
4 & 25 & 0.17 & Home-kindergarten cooperation \\
5 & 25 & 0.11 & Children remaining in rural area \\
6 & 20 & 0.53 & kindergarten \\
7 & 18 & 0.27 & Rural area \\
8 & 17 & 0.20 & Preschool floating children \\
9 & 14 & 0.22 & Parents of infant \\
10 & 12 & 0.20 & strategy \\
\hline
\end{tabular}

Cite Space, v. 5.6.R5 (32-bit)

July 13, 2020 4:22:51 PM CST

Wos: C:IUserslconglDesktoplcitespace data 11data

Timespan: 2000-2019 (Slice Length=1)

Selection Criteria: Top 100 per slice, $\mathrm{LRF}=3.0, \mathrm{LBY}=8, \mathrm{e}=2.0$

Network: $N=66, E=99$ (Density=0.0462)

Largest C C: $60(90 \%)$

Nodes Labeled: $1.0 \%$

Pruning: Pathfinder

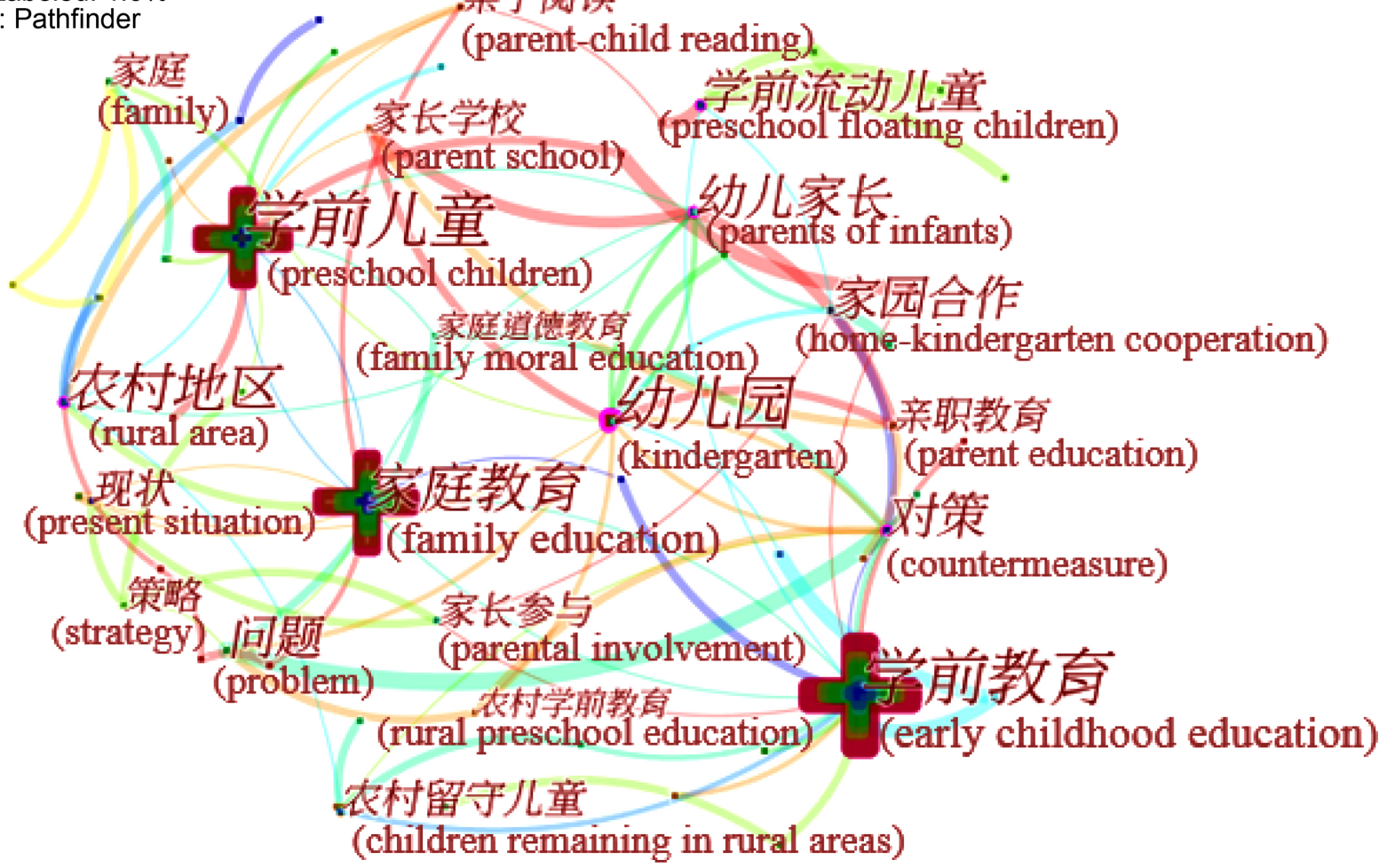

Figure 2. Keywords Co-occurrence of early childhood family education in CNKI.

home-kindergarten cooperation research, family education research for rural left-behind children, family education research for urban floating children and research on parents of preschool children. 
Chinese urban rural polarization characteristics of geographical environment and social environment caused part of the rural preschool children follow working parents come to city to life and learning to be flow of preschool children, the other part of pre-school children are remained by migrant parents to their rural relatives especially their grandparents to study and live, which are called rural left-behind children, these two types of preschool children's family education problems worthy of attention. At present, a series of psychological and occupational safety problems of left-behind children in rural areas have become the focus of their family education (Guo, 2017). Parents also need to pay attention to the implementation of family education for floating preschool children, because children follow their parents from rural areas to study in cities, and the change of environment will have a certain psychological impact on children.

\subsubsection{Keywords Clustering Analysis}

Keywords co-occurrence frequency has certain directivity on research hotspots. From 2000 to 2020, research hotspots in the field of early childhood family education in China have emerged. However, clustering analysis of keywords is still needed to explore research topics and dig out internal relations. Cluster analysis was carried out on the interface where CiteSpace software had formed a keyword co-existing network map, and keyword clustering was selected. Under LLR algorithm, the clustering modularity index $\mathrm{Q}$ value was $0.5738(\mathrm{Q}>0.3$ significant community structure), clustering profile index $\mathrm{S}$ value was 0.5169 ( $\mathrm{S}>0.5$ reasonable clustering) of the keyword clustering map.

The keyword clustering in Figure 3 can reflect the research topics in the field of family education for preschool Children in China mainly include preschool children education, parent education, learning in regular class, personality development, preschool floating children, early childhood education and family psychological environment.

\subsubsection{Keywords Bursts Term Analysis}

Keyword Burst Detection algorithm in CiteSpace software can track the active state and new trend of research literature data. On the basis of the completion of keyword co-occurrence and clustering graph, keyword burst detection was carried out. The algorithm and number were set as default values. The minimum burst duration was 2 years, and a total of 12 burst keywords were detected. The results of the keyword burst detection are shown in Figure 4.

There are two burst keywords near the current time, namely parenting education and parent school. It can be seen from the figure that the forefront trend of early childhood family education in China is the research on parental education of preschool children. As the caregivers of preschool children, love for their children is instinctive, but how to scientifically educate and guide children growth needs parental learning and training.

\section{Discussion}

A total of 582 research literature on early childhood education from CNKI were 
Cite Space, v. 5.6.R5 (32-bit)

July 12, 2020 6:15:24 PM CST

Wos: C:IUserslconglDesktoplcitespace data 1ldata

Timespan: 2000-2019 (Slice Length=1)

Selection Criteria: Top 100 per slice, $\mathrm{LRF}=3.0, \mathrm{LBY}=8, \mathrm{e}=2.0$

Network: $\mathrm{N}=65, \mathrm{E}=98$ (Density $=0.0471$ )

Largest C C: 59 (90\%)

Nodes Labeled: $1.0 \%$

Pruning: Pathfinder

Modularity $\mathrm{Q}=0.5738$

Mean Silhouette $=0.5169$

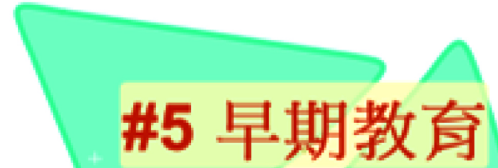

(early childhood education)

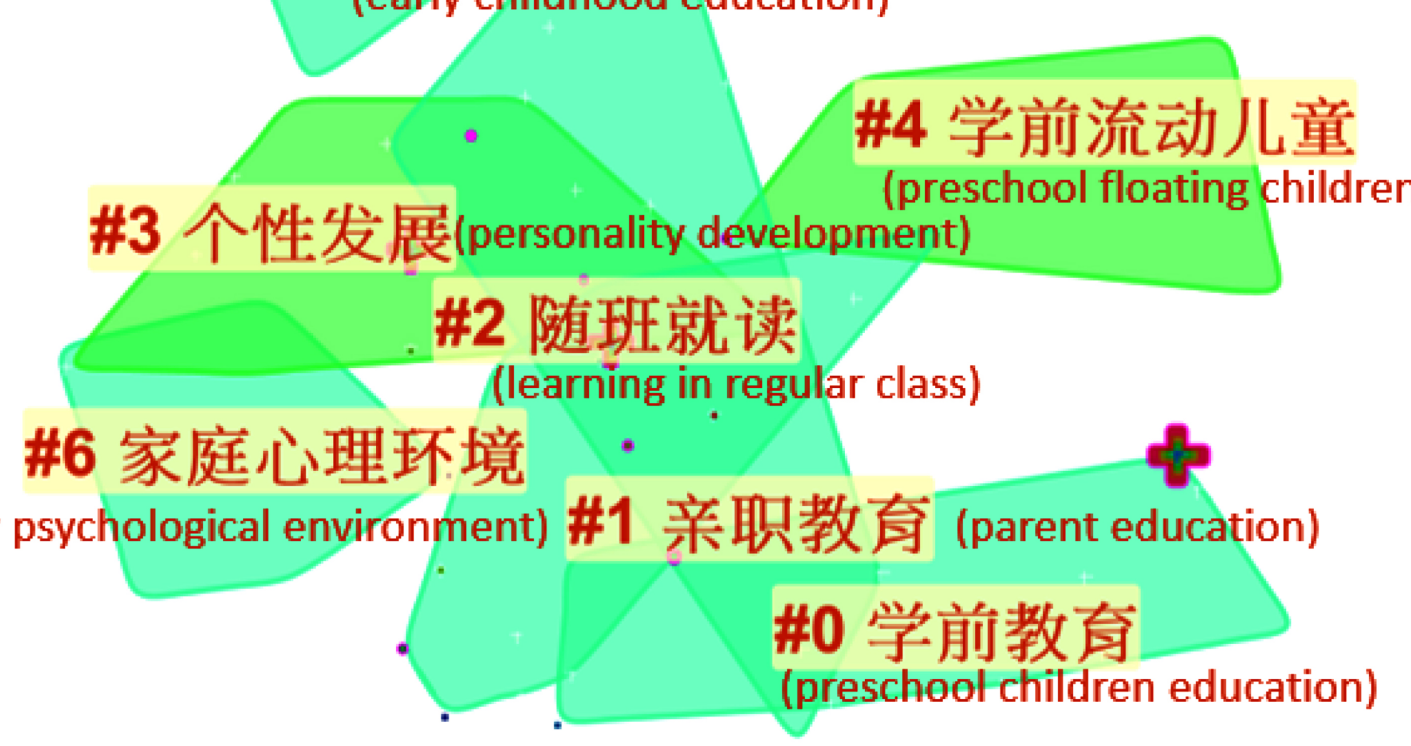

Figure 3. The keywords clustering graph of early childhood family education research literature in CNKI.

Top 12 Keywords with the Strongest Citation Bursts

$\left.\begin{array}{lrlll}\text { Keywords } & \text { Strength Begin End } \\ \text { Community } & 2.0621 & 2008 & 2012 \\ \text { Home-Kindergarten Cooperation } & 2.3008 & 2009 & 2011 \\ \text { Children remaining } & 2.3601 & 2011 & 2012 \\ \text { Rural areas } & 2.0145 & 2012 & 2013 \\ \text { Parent of infants } & 2.7266 & 2013 & 2015 \\ \text { Minority } & 1.7513 & 2015 & 2016 \\ \text { Chen He Qin } & 0.9721 & 2015 & 2016 \\ \text { Suggestion } & 1.3192 & 2016 & 2018 \\ \text { Strategy } & 1.3541 & 2016 & 2017 \\ \text { Family } & 2.3076 & 2016 & 2017 \\ \text { Parent education } & 1.6073 & 2018 & 2020 \\ \text { Parent school } & 1.6073 & 2018 & 2020\end{array}\right]$

Figure 4. Keyword burst detection results of early childhood family education research literature data from CNKI.

used as data sources, which were imported into CiteSpace software for quantitative and visual analysis. The first two research papers in this research field were published in 2002, and the number of papers published in this field has steadily 
increased since then. The two authors with the highest volume of publications are Miao Chun Feng and Shu Tan respectively. The institution with the highest publication volume is East China Normal University, with a total of 30 publications. Based on keyword co-occurrence analysis and keyword clustering analysis, the research data shows 10 high-frequency and high centrality keywords and 6 keywords clusters, and combining with literature content analysis can determine the research hotspots in the field of early childhood family education in China are the home-kindergarten cooperation research, rural preschool left-behind children family education research, preschool floating children family education research and preschool children parental education research. In addition, the research trend in the field of early childhood education in China is parental education and parent school through keyword burst detection and calculation. As a way to implement parental education, parent school is included in parental education for discussion.

\subsection{Home-Kindergarten Cooperation Research}

Home-kindergarten cooperation has become a research hotspot in the field of family education for preschool children in China because kindergartens and families are the main places for preschool children to receive education. Only by maintaining consistent training goals can kindergartens and families promote the all-round development of children. Chinese programmatic document on preschool education emphasize that children families and kindergartens should become partners in promoting children's development, and that cooperation between homes should adhere to the principles of respect and equality (Chinese Ministry of Education, 2001, 2012). Home-kindergarten cooperation is neither traditional parent work nor kindergarten-based parent cooperation, but the hand in hand of two social organizations and members that also shoulder the responsibility of life enlightenment and education (Zhang, 2009).

However, there are still many difficulties in home-kindergarten cooperation in China, which focuses more on the acquisition of children's subject knowledge, the cooperation route mainly through open days for parents, and the center of gravity of cooperation is inclined to the kindergarten (Cao, 2003; Yuan, 2015). Some researchers carried out studies on home-kindergarten cooperation in developed countries, and advocated that the educational content of home-based co-parenting in China should be based on children's identity, role and relationship, surrounding environment, sports, safety, health, food and other aspects, rather than just educational cooperation of subject knowledge (Li, 2003). In addition to the open days for parents of kindergartens, Chinese Ministry of Education should also use modern information technology to build a network cooperation platform for preschool children's families and kindergartens, so that cooperative information sharing can take place at anytime and anywhere. The unequal cooperative status causes the parents to become the bystanders of early childhood education for a long time. However teachers need to constantly re- 
mind themselves to pay attention to the "surrogate parent relationship" between themselves and children (van Manen, 2001). The goal of promoting the growth of children must be achieved by families and kindergartens on the basis of equal and sincere communication.

\subsection{Rural Preschool Left-Behind Children Family Education Research}

In China, when both parents or one parent move to other regions, children are left behind in the place where they have their registered permanent residence, those below aged 6 unenrolled children who cannot live with both parents are called preschool left-behind children (Zhang \& Cai, 2009). After China adopted reform and opening up, the free movement of labor force began with the purpose of seeking employment in other places. Restricted by economic conditions and the dual structure system between urban and rural areas, many peasant workers cannot enter cities to work while raising their preschool children (Wei, 2007). The peasant workers have to leave their children in the countryside and entrust others to take care of them. Therefore, most preschool left-behind children exist in rural areas in China.

In 2000, there were 19.81 million left-behind children in rural areas of China, rising to 58.61 million in 2005. In just five years, the number of left-behind children in rural areas has nearly tripled. Meanwhile, the percentage of left-behind children among all children rose from 8.05 percent in 2000 to 21.72 percent in 2005 , among them, preschool left-behind children account for $41.58 \%$ of the left-behind children in rural areas, up to 9,523,700 people, and the trend is increasing year by year (Duan, Lv, Guo, \& Wang, 2013). The education of the huge preschool left-behind children in China deserves social attention, especially their family education. Left-behind children in rural areas are unable to stay with their parents for a long time, and lack of affection, care and education, which makes them lag behind other children of the same age in many aspects of physical and mental development. A study of 1780 pre-school left-behind children in rural areas found that the development of pre-school left-behind children in rural areas is mainly characterized by poor nutrition and health, emotional communication disorders, blocked early intellectual development and other prominent problems (Chen, 2018). Grandparents are the main caregivers of left-behind children after their parents leave home. At present, the education level of grandparents of 0 - 6 years old children in China is still very low, which will directly affect their attitudes, methods and values of early childhood family education.

Current rural preschool left-behind children family removed education mode has the serious lag, this is not conducive to children's healthy growth and sustainable development of society, so the lack of family education requires the government to provide effective public services, and the legitimacy of the government's existence also requires the government to provide public services to 
the public. The government purchases family education services for preschool left-behind children in rural areas through diversified providers such as rural kindergartens, professional education institutions, education experts and scholars, and public welfare organizations (Yang, Hu, \& Yang, 2018). These providers not only provide family education guidance for rural preschool left-behind children, but also provide psychological counseling, emotional comfort, life and learning guidance, so as to alleviate a series of physical and psychological problems caused by the lack of family education for rural preschool left-behind children. In addition, the government is also making efforts for rural pre-school left-behind children to live with their parents who are peasant workers in cities, which is also another research hotspot in the field of early childhood family education in China: research on preschool floating children family education.

\subsection{Preschool Floating Children Family Education Research}

Preschool floating children refer to children who move to another area with their parents because their parents need to leave their place of residence due to work or other reasons. According to the data of Chinese sixth national population census, there were 36 million migrant children in China, among which the number of preschool migrant children was 8.99 million, accounting for $25 \%$ of the total number of floating children, which is an increase of 1.91 million and nearly $26.91 \%$ compared with 2005 (Duan, Lv, Wang, \& Guo, 2013). In the process of children's frequent mobility with their parents, the constant change of environment is difficult to provide a safe psychological environment for preschool floating children, and the mobile experience in early childhood may easily lead to some mental health problems (Dan, 2016). There are significant differences between preschool floating children and local children in mood disorder, character defect and conduct disorder, and their mental health development level significantly lower than local children. Mental health problems in childhood are more directly linked to the environment than at any other time in a person's life. Children's development is a process of interaction between individuals and the surrounding environment, and family is the most important place for preschool children's development. Family material environment and spiritual environment have a great impact on preschool children's psychology and mental health. A number of studies have shown that preschool floating children's family education resources are insufficient, parents' ideas are not scientific, such as having high expectations and paying more attention to knowledge learning, parent-child communication opportunities are less, and parents and children often have conflicting ideas (Suo \& Dan, 2013; Wang \& Wang, 2014).

To create a harmonious family atmosphere and promote the physical and mental health development of preschool floating children, parents should change their educational concept at first. Peasant worker parents need to spend more time with their children after a day's work, such as reading, playing and talking with their children. Parents should seek professional help when they find 
emotional abnormalities in their preschool floating children. The government should establish professional support groups for preschool floating children to provide professional guidance to their families, and make great efforts to solve the problem of preschool migrant children's limited access to public kindergartens. The community should also provide more help for parents of preschool floating children, such as organizing parent-child outdoor activities with community resources during holidays. The family education of the preschool children of peasant workers in China needs more macro-policy support from the government, because the preschool children of peasant workers have only two choices: to say goodbye to their parents and be left behind to live with grandparents or other caregivers in the rural areas, or to follow their parents and leave their rural hometown for a completely unfamiliar urban environment. With the growth of Chinese economy and the acceleration of urbanization, the number of peasant workers in cities is increasing day by day, and the number of rural preschool left-behind children and preschool floating children in rural areas is also increasing significantly. Whether preschool children should be left or taken away, the most essential issue is to solve the family education problem of left-behind children and floating children. Only in this way can peasant parents make such a difficult choice to support the physical and mental development of preschool children.

\subsection{Preschool Children Parental Education Research}

Parental education is a foreign term, in the above CiteSpace quantitative and visual analysis results can be seen in the 2011 preschool children parental education in China first appeared in the academic research literature, and beginning in 2018 to become burst keywords continues today. Therefore, parental education for preschool children has become a research hotspot and frontier in the field of family education for preschool children in China. Previously, it was widely believed that the development of habits formation, cognition improvement, character building and quality improvement of preschool children only depended on parental own experience, which was taught by words and deeds from generation to generation. It was not until the term "parental education" was introduced that people realized that parents of preschool children also need training.

Parental education refers to providing parents with knowledge and skills in parenting, with the purpose of helping parents to be effective parents, to play the role of parents successfully, to take on the responsibilities of parents, and to promote the healthy growth and development of children (Wang, 1999). Early childhood stage is a critical period for the formation of individual personality and the best period for children's social, behavioral and language development. Parental education is the most effective strategy to prevent, intervene and reduce improper parenting and problematic behavior of preschool children (Petersson et al., 2004). Therefore, children in preschool families are regarded as the most 
important period to implement parental education.

Parental education for preschool children in China is implemented in a single way, with kindergartens as the main body. The kindergarten carries out parental education through parent-child games, garden parties, parents meetings, expert lectures, open days and parents experience exchange activities (Zhang, Lu, \& Liu, 2019). However, parents of infants and toddlers who are not enrolled in the kindergarten do not have access to parental education. A study with a sample of 1201 parents of preschool children found that the parental education needs of parents are diversified, among which the knowledge and skills of child rearing rank first, and the cultivation of good behavior habits is the most urgent. The second is communication and adjustment needs, and parent-child interaction communication is the most urgent. Thirdly, family management needs, and family crisis management is the most urgent (Xu \& Zhou, 2016). In view of the current plight and unmet educational needs of parental education for preschool children in China, The Chinese government, kindergartens, communities and parents should take positive measures to improve parental education. At the 12th National People's Congress in 2017, Cao Dewang, a member of the Chinese People's Political Consultative Conference (CPPCC), proposed to enact China's Parent Education Law, making parenting education an obligation. The main body of education implementation should not only be undertaken by kindergartens, but diversified forms of parenting education activities should be carried out through multiple channels, such as setting up community parent schools, opening family education care hotline, setting up family care promotion association, increasing parental education volunteers to provide door-to-door guidance, and using the Internet to set up online parent schools (Shu, 2020). The training of parent education workers can improve the quality of parent education, because parent educator teachers can use scientific and effective means to guide parents. Chinese Ministry of Education needs to establish the parental education instructor certification system as soon as possible, and at the same time, issue the guidance curriculum outline of parental education to provide professional personnel for parenting education.

\section{Conclusion}

In this article, CiteSpace software was used to conduct quantitative and visual analysis of research literature in the field of early childhood family education in China, and then literature content analysis was combined to understand research hotspots and frontiers in this field. The discussion part of the article has clarified that the hotspots in the field of early childhood family education in China are home-kindergarten cooperation research, rural preschool left-behind children family education research, preschool floating children family education research and preschool children parental education research.

Among them, the main problem in home-kindergarten cooperation in China is that the relationship between parents and kindergartens is not equal. Parents are mostly required to be the coordinators and bystanders of kindergartens. In 
order to better promote the all-round development of children, kindergartens and parents should communicate and cooperate on an equal footing. The ways of co-education between families and kindergartens can also be enriched, such as campus open day, parent assistant program, parent committee and network communication platform, all of which can increase the effectiveness of cooperation between families and kindergartens to promote children's development.

In addition, rural preschool left-behind children family education and preschool floating children family education, this pair of social phenomena caused by Chinese urbanization construction deserves wide attention (Li \& Reng, 2013). Chinese rural preschool left-behind children and the floating children is shortcomings in China's social transformation and development, sometimes reality forced and had to leave the children in rural to grandparents or had to follow rural migrant parents between different cities. These two special children groups and their parents need to get more policy support, such as the entering schools in cities. Rural government departments in China need to develop more activities to care for left-behind children and strategies to improve grandparents' educational awareness, and urban government departments should also speed up the problem of migrant children entering schools in cities.

Finally, parental education for preschool children, as a foreign term, was studied very late in China, and the first formal research literature was published in 2011. Therefore, this research hotspot also serves as the research frontier in the field of early childhood family education. The current situation of parenting education for preschool children in China is that it cannot meet the needs of parents, with a single form, lack of professional guidance personnel and lack of legal environment. Drawing on the practical experience of the internationally widely used quality parenting education project, including Parent Management Training, Helping The Noncompliant Child, Parent-Child Interaction Therapy, The Incredible Years and Triple P Positive Parenting Program (Fan, 2016), the government, the community, kindergartens and parents of children work together to provide development opportunities for parenting education of preschool children in China.

\section{Conflicts of Interest}

The authors declare no conflicts of interest regarding the publication of this paper.

\section{References}

Cao, D. D. (2003). Home Cooperation Dilemma Analysis. Studies in Early Childhood Education, 7, 97-98.

Chen, C. M. (2006). CiteSpace II: Detecting and Visualizing Emerging Trends and Transient Patterns in Scientific Literature. Journal of the American Society for Information Science and Technology, 2, 359-377. https://doi.org/10.1002/asi.20317

Chen, G. X. (2018). Development Dilemma of Preschool Left-Behind Children in Rural Areas and Its Solutions. Chinese Journal of Education, 1, 65-66. 
Chen, Y., Chen, C., Liu, Z., Hu, Z., \& Wang, X. (2015). The methodology Function of CiteSpace Mapping Knowledge Domains. Studies in Science of Science, 2, 242-253.

Chinese Ministry of Education (2001). Guidelines for Kindergarten Education. Chinese Ministry of Education.

Chinese Ministry of Education (2012). Guidelines for Learning and Development for 3-6 Year Olds. Chinese Ministry of Education.

Dan, F. (2016). A Qualitative Study of Family Environment of Preschool Migrant Children with Mental Health Problems. Journal of Shenyang Normal University: Social Science Edition, 6, 132-136.

Du, L. (2006). On the Deficiency of Rural Preschool Children Family Education. Journal of Hotan Normal College, 6, 68-69.

Duan, C. R., Lv, L. D., Guo, J., \& Wang, Z. P. (2013). Survival and Development of Left-Behind Children in Rural China: Based on the Analysis of Sixth Census Data. Population Journal, 3, 37-49.

Duan, C. R., Lv, L. D., Wang, Z. P., \& Guo, J. (2013). The Survival and Development Status of Floating Children in China: An Analysis of the Sixth Population Census Data. South China Population, 4, 44-55.

Fan, J. Q. (2016). Experience and Enlightenment of the International Family Parenting Education Project for Early Childhood. Studies in Early Childhood Education, 11, 3-16.

Guo, F. T. (2017). Problems and Changes of Family Education Mode for Left-Behind Children. Education Comments, 10, 25-29.

Guo, H. D. (2012). Problems and Countermeasures of preschool Children's Family Education. Journal of Qiqihar Engineering Institute, No. 4, 8-9.

Li, H. (2010). Get Rid of the Misunderstanding of Preschool Children Family Education. Education Science \& Culture Magazine, 4, 5-7.

Li, S. L. (2003). Research on Cooperation between Kindergarten Family and Community. East China Normal University Press.

Li, Y., \& Reng, J. T. (2013). Current Situation and Suggestions of Family Education Guidance Service for Floating and Left-Behind Children in China. Journal of Capital Normal University (Social Sciences Edition), 5, 158-162.

Petersson, K., Petersson, C., \& Hkansson, A. (2004). What Is Good Parental Education? Scandinavian Journal of Caring Sciences, 18, 82-89. https://doi.org/10.1111/j.1471-6712.2004.00260.x

Qiu, S., Pan, L., \& Hou, J. (2014). Hot Topics and Developments Involving International Early Childhood Education in the 21st Century-Based on an Analysis of Literature Research into the Top 5 Early Childhood Education. Studies in Early Childhood Education, 6, 11.

Research Group on the Characteristics, Ideas and Methods of Family Education in the New Era, Ministry of Education Care for the Next Generation Working Committee (2012). The Present Situation, Problems and Policy Suggestions of Family Education in China. People's Education, No. 1, 6-11.

Reti, I. M., Samuels, J. F., Eaton, W. W., Bienvenu Iii, O. J., Costa, P. T., \& Nestadt, G. (2002). Influences of Parenting on Normal Personality Traits. Psychiatry Research, 111, 55-64. https://doi.org/10.1016/S0165-1781(02)00128-2

Shu, T. (2020). Strategies to Promote the Development of Parent Education for Preschool Children. Chinese After-School Education, 1, 1-2.

Spera, C. (2015). A Review of the Relationship among Parenting Practices, Parenting Styles and Adolescent School Achievement. Educational Psychology Review, 17, 125-146. 
https://doi.org/10.1007/s10648-005-3950-1

Suo, C. Q., \& Dan, F. (2013). A Survey on the Current Situation of Family Education of Floating Children Aged 3-6 Years: A Case Study of Shenyang. Early Education (Teaching and Research Edition), 9, 51-53.

van Manen, M. (2001). The Tact of Teaching: The Meaning of Pedagogical Thoughtfulness. Educational Science Publishing.

Wang, S. L. (1999). A Survey Study on the Parents' Advice for Junior High School with Disabilites in Middle Part of Taiwan. National Changhua Normal University.

Wang, X. F., \& Wang, Y. N. (2014). A Study on the Current Situation of family Education for Floating Children Aged 3-6. Jiangsu Early Childhood Education, 1, 8-12.

Wei, L. Y. (2007). Investigation on the Current Situation of Family Education for Left-Behind Children in Rural Areas: A Case Study of Huaiyuan Town Yizhou City Guangxi. Family Education in China, 2, 34-40.

Xu, L. Y., \& Zhou, N. L. (2016). On the Present Status and Needs for Parent Education of Preschool Children in China. Studies in Preschool Education, 3, 57-66.

Yang, J., Hu, Q. S., \& Yang, H. (2018). Research on the Family Education Service Mechanism of Rural Left-Behind Children Purchased by the Government. Rural Econo$m y$, 3, 106-111.

Yin, F. (2003). Study on the Status Quo of Parent-Child Games among Children in Chongqing Main Urban Area. Southwest Normal University.

Yuan, X. L. (2015). A Study on the Current Situation of Home-Kindergarten Cooperation in Kindergarten Management: A Case Study of H Kindergarten in Huai'an City Jiangsu Province. Minzu University of China.

Yue, A. F. (2003). Since 1978 Kindergarten and the Value of Family Relationship Policy Analysis in China. Shandong Normal University.

Zhang, N., \& Cai, Y. Q. (2009). On the Difficulties and Requirements of Left-Behind Children under Different Care-Taking Modes. Studies in Preschool Education, 5, 31-36.

Zhang, X. T., Lu, Q. H., \& Liu, T. E. (2019). The Statue Quo of Parental Education of Preschool Children's Parents in Xiangyang City. Journal of Chengdu Normal University, 5, 43-48.

Zhang, Y. (2009). Research on the Cooperation Status of Kindergarten Homes: A Case Study of Kindergartens in Chongqing. Southwest University. 